\title{
Consumer Healthcare Technology Usage Impacting Behavior
}

\author{
Lyndsey Lumpkin \\ Bellevue University \\ Cronin-Gilmore \\ Bellevue University
}

\begin{abstract}
Consumers continue adopting healthcare technology, from wearable devices to patient portals to telehealth. Researchers must endeavor to understand how this technology impacts behavior and health perceptions. The hypothesis is technology helps individuals to better understand, track, and interact with their health. Objectives include identifying if wearable technology impacts health consciousness, understanding digital patient portal usage, ascertaining if digital prescriptions are considered valuable, and identifying if telehealth is viewed as effective. A literature review informed the qualitative survey and exploratory focus group research. The study revealed positive sentiment towards new technology and strong consumer influence, supporting the need for additional research.
\end{abstract}

Keywords: consumer healthcare technology influence, wearable healthcare devices, telehealth, digital patient portals, consumer health-tech use and impact

\section{TOPIC OVERVIEW}

Technology advancements have progressed throughout the healthcare industry. Consumer healthcare technology has become prevalent in everyday life, spurring continuous innovation. This includes advancements from traditional technology companies like the introduction of the Apple Watch, new health tracking devices like Fitbit, and patient-related breakthroughs such as electronic health records and patient portals. Virtual healthcare services, known as telehealth, have also become more common among consumers. Brands like Teladoc and Talkspace are now household names that have normalized the use of remote healthcare services. As consumers continue using technology to augment personal healthcare practices, there is a need to better understand how technology influences their healthcare perceptions.

\section{PROBLEM/HYPOTHESIS}

Technology provides tools for individuals to better understand, track, and interact with their health and healthcare teams. 


\section{PURPOSE OF STUDY}

Consumers increasingly use a variety of healthcare-related technology that potentially influences their perception of personal health and the perception of their related healthcare teams. The focus of this study is to understand if consumer healthcare technology including patient portals, electronic health records, digital prescriptions, wearable devices, and telehealth services provide an outlet for consumers to have more positive interactions with their health and healthcare teams. As the potential for tracking and interacting digitally with health-related technology increases, researchers must understand how the usage impacts consumer perceptions and behaviors.

\section{RESEARCH OBJECTIVES}

1. To identify if wearable technology positively impacts a consumer to be more health conscious.

2. To confirm if digital patient portals, such as digital patient files or appointment setting mechanisms, help the end user interact more efficiently with the healthcare service.

3. To understand if people find value when using digital resources for filling and tracking prescriptions.

4. To understand if telehealth services are viewed as effective by the individual using them.

\section{LITERATURE REVIEW}

\section{Consumer and Policy Influence}

An early definition of eHealth described it as healthcare related to the internet as well as technology influencing the fields of medical informatics, public health, business, and health and information services (Eysenbach, 2001). Researchers identified the need to assess skills related to seeking, appraising and applying situations related to eHealth resources and developed a scale to measure eHealth literacy (Norman \& Skinner, 2006). Using the eHealth literacy scale, another study found that the female gender, younger ages, and high eHealth literacy correlated with seeking internet-related health resources (Madrigal \& Escoffery, 2019). The influence of eHealth literacy on a person's health technology adoption increases the importance of researching consumer adoption, usage and perceptions. For the purposes of this study, all technology discussed is consumer/patient-facing and includes a review of patient portals, electronic health records, digital prescriptions, wearable devices, and telehealth services.

In more recent years, the use of electronic resources for healthcare advancement has grown. The HIPAA, HITECH, and Cures Act have governed individual access to digital healthcare records, but researchers argue for increased oversight because current regulations have not kept pace with technology development and consumer demands, creating ambiguity and confusion (Rosenbloom et al., 2019). One study measured the adoption of patient portals before and after the Stage 2 Meaningful Use government program and found significant increases after the program launched (Turner et al., 2019). This research suggests the influence of incentive programs on effective consumer adoption. Another study on wearable devices and insurance incentives found that Americans are willing to use wearable devices if there are health and/or economic motivations (Soliño-Fernandez et al., 2019). Some are calling for FDA regulation of health and wellness apps claiming that the lack of policy results in oversight by technology developers (Kasperbauer \& Wright, 2020). With increased scrutiny of healthcare technology's influence on individuals and public healthcare policies, researchers should seek to understand how technology influences consumer behavior.

A global business survey found that consumer healthcare technology usage slowed in the years before the pandemic but saw an uptick after distancing began (Safavi \& Kalis, 2020). A study of one telehealth company found an increase in usage during the global Covid-19 pandemic but attributed the uses to visits for behavioral or chronic health issues (Uscher-Pines et al., 2020). The Covid-19 pandemic created a catalyst event that potentially increased overall adoption of remote telehealth services. 


\section{Patient Portals and Electronic Health Records}

A recent observation of patient portals and electronic health record adoption found low physician and patient usage for reasons including trouble incorporating it into daily work, viewed as difficult to use or costly, and disconnected causing patients to have multiple portals (Pratt, 2017). Emerging trends such as interoperability and growth in patient-focused technology address some of the challenges in the healthcare industry (Pratt, 2017). Another study examining 15 years' worth of historical literature on electronic health records found key themes of anticipated benefits, doctor-patient trust, technology and privacy, and ethics as well as general acknowledgement of the technology's potential to improve healthcare with limitations (Gariépy-Saper \& Decarie, 2021). This highlights the need for more patient and user adoption research to inform healthcare technology development.

An additional study looked at indicators of individual patient portal adoption and found the biggest contributors were expected performance, expected effort, social influence, and habit (Tavares et al., 2018). This provides insight into individual motivators when navigating healthcare technology and informs the research study. A cross-country comparison between America and Portugal found the US to be more advanced overall in adoption (Tavares \& Oliveira, 2017). As the US continues to develop healthcare technology, there is a need to research and understand the influence of consumer adoption. A health information exchange study found patients perceived the technology to be intrusive when the data collection practices were not transparent, incorrect data was collected and not easily accessible for editing, the patient does not feel informed on the physicians use of the electronic records, and when patients aren't sure how to access their private data (Esmaeilzadeh, 2019). One study of electronic health records used with psoriasis patients and doctors found patients regarded the technology as important and beneficial, but physicians were skeptical (Klein et al., 2020). This suggests that consumers motivated by ongoing care may have stronger positive perceptions of facilitating healthcare technology.

\section{Wearable Health Tracking Devices}

Wearable devices are a common product among consumers, for health and fitness reasons like Fitbit or for general purposes with added health benefits like the Apple Watch. An adoption intent study found health belief, health information accuracy, the consumer's perception of the wearable device as useful, and peer influences correlated with wearable device adoption (Cheung et al., 2019). Another study found that participants viewed the wearable device as part of a larger ecosystem related to their fitness goals with patterns such as general goals indicating the highest usage, specific fitness targets showing loyal but varying patterns of usage and nutrition-related goals indicating higher product switching and irregular use (Canhoto \& Arp, 2017). This shows individual perception of health may impact the usage of the wearable device. Additionally, researchers found participant's perception of physical activity and steps resulted in higher motivation than participants with actual high activity and steps, indicating perception holds more importance than actual activity (Kinney et al., 2019).

Wearable devices could impact community healthcare as well. One study saw significant improvements in the ability to predict influenza outbreaks after incorporating sleep and resting heart rate data, suggesting the ability to harness wearable device data to influence real time public health (Radin et al., 2020). With the varying usage and perception patterns, it is important to study any correlations between wearable devices and healthcare perceptions or implications.

\section{Telehealth}

Telehealth has seen increased usage through expanded healthcare industry adoption and the recent pressures from the pandemic. One study found an increased interest in telehealth when access to physical services were limited, and this was particularly common in rural areas (Weinzimmer et al., 2021). Rural clinical staff members were able to define telehealth services and uses but expressed concerns for its ability to maintain and use as well as the cost and privacy (McClellan et al., 2020). Another study found low adoption of telehealth services with only a small percentage of pediatricians reporting using it and majority of those focused on the western region, in medical school, or specialists (Sisk et al., 2020). For Hispanic Texas border communities, researchers identified that there was little knowledge of telehealth services, but 
once explained responses were positive and indicated likelihood of use, drawing connections between eHealth literacy and adoption (Ghaddar et al., 2020).

Telehealth has expanded into new uses and technology applications. Artificial intelligence-based virtual physicians left participants feeling comfortable with the idea of receiving care from this type of service, citing the low cost and convenience as a positive but also had concerns about data privacy and misdiagnosis (Goetz et al., 2020). One study found that respondents were more willing to use telemedicine when it was their normal provider and less willing if not involved in primary practice (Welch et al., 2017). As telehealth technology continues to grow, it is important to understand consumer perception and the relationship created between the technology and the patient consumers.

\section{METHODOLOGY}

The research used in this report includes both exploratory and descriptive research. The descriptive research was collected by using a quantitative survey shared by link to 26 respondents. The questionnaire was designed to identify usage and influence details as it relates to the consumer healthcare technology. Before the survey was conducted, an exploratory literature review was completed to inform the research. The exploratory research was conducted using a focus group of six individuals. A series of questions were asked to explore the participant's perceptions of consumer healthcare technology.

\section{QUANTITATIVE FINDINGS}

\section{Objective 1: Does Wearable Technology Positively Impact a Consumer to Be More Health Conscious?}

60 percent of respondents reported using wearable devices. This response supports the identified lagging adoption in other reports (Safavi \& Kalis, 2020). 78 percent of respondents also reported high or moderate usage breaking down as 39 percent very frequently, 17 percent frequently, and 22 percent occasionally wearing the device. Additionally, checking the device data was high with 73 percent of respondents regularly checking their device at intervals of occasionally (28 percent), frequently (28 percent), and very frequently (17 percent).

Although usage is high among device users, only 24 percent report connecting their device to other health tracking apps. Those who did pair with apps named workout and health-related apps such as running trackers, workout and activity trackers, and health insurance apps. This finding is consistent with research discovered in the review. Users were highly motivated to use the trackable device by daily steps (59 percent), health metrics tracking (55 percent), weight loss (nine percent), health goal maintenance (36 percent) and athletic training ( 27 percent). Conversely to previous studies, only nine percent of respondents reported being motivated by peer involvement.

\section{Objective 2: Do Digital Patient Portals, Such as Digital Patient Files or Appointment Setting Mechanisms, Help the End User Interact More Efficiently With the Healthcare Service?}

Patient portals were reported as frequently used with 72 percent of respondents using the digital resource most or some of the time. When asked about motivations for using the portals, utility functions were highly recognized including 68 percent identifying bill pay, health records, and paperwork as a top motivator. Managing appointments (64 percent), updating insurance (52 percent), and requesting prescriptions (40 percent) were also identified as motivating. This suggests that patient consumers using digital portals prefer utility features.

When asked if in agreement with the statement 'I prefer using a digital patient portal when interacting with healthcare providers' a 60 percent majority of respondents said agree or strongly agree. Only four percent of respondents disagreed with the statement and 36 percent found it to be neutral. This indicates a comfort with digital resources as consumers begin to adopt patient portals more often and some even using it as their preferred method for interacting with the care team. This also supports other research identifying patient preferences for digital tools. When asked if the digital portals made their healthcare interactions 
easier, 91 percent responded with some indication it positively influenced their interaction. This implies consumers find patient portals useful and the use of the digital portals positively impacts their opinion of the healthcare teams.

\section{Objective 3: Do People Find Value When Using Digital Resources for Filling and Tracking Prescriptions?}

Digital prescription requests were overwhelmingly used by respondents with 96 percent using the option most of the time. For recurring prescriptions, 87 percent of respondents were somewhat likely or very likely to order online. Top reasons respondents used digital tools to manage prescriptions included confirming pharmacy status (70 percent), checking payment details (48 percent), requesting physician updates (35 percent), and confirming shipping status (22 percent). This study indicates digital prescription services are favorably considered by consumers with preferences for utility functions within supporting digital tools. This has implications for not only the prescription process but also the digital portals and access points consumers are using to manage the digital interactions.

\section{Objective 4: Are Telehealth Services Viewed as Effective by the Individual Using Them?}

Telehealth services were used by 76 percent of respondents. The high usage response may be attributed to the impacts of the global Covid-19 pandemic, a catalyst event for remote services. Respondents ranked time convenience followed by location convenience as the top two influencing factors when choosing to use telehealth services. This suggests that convenience is a top factor when patient consumers are deciding to use remotes services. Respondents had mixed feelings about the quality of telehealth care, reporting the services as 45 percent good, 32 percent acceptable, 14 percent very good, five percent poor and five percent very poor. When asked if they would choose telehealth over an in-person visit, 71 percent indicated potential and 29 percent indicated no potential. This supports other research suggesting consumers are open to or already adopting telehealth options. However, the adoption is not as positive as other consumer healthcare technology.

\section{QUALITATIVE FINDINGS}

\section{Wearable Devices}

1. Goals. Overall theme: Accountability and guilt.

Wearable devices create a sense of accountability to activity goals and if not met, feelings of guilt are experienced.

2. Competition. Overall theme: Personal and shared motivation.

Motivated by competition with one's own self, others, or both to beat activity-based goals.

\section{Patient Portals}

3. Convenience. Overall theme: Time and access.

Shared affinity for convenience in the form of centralized access to doctors, information, and utility functions such as payments or appointment setting limiting the wasted time by users.

\section{Digital Prescriptions}

4. Control. Overall theme: Flexibility and immediacy.

Preferences for controlling the prescription process through digital means creating flexibility and immediacy benefits.

\section{Telehealth}

5. Uncertainty. Overall theme: Covid and distrust.

Uncertainty expressed related to feeling forced by Covid into the telehealth services, unsure of expectations, and distrust in the accuracy of diagnoses due to the method. However, while the 
diagnosis was not trusted, overall, the doctor was cited as providing a voice of authority and comfort.

6. Therapy. Overall theme: Comforting setting.

Therapy was treated differently than traditional doctors, with preferences towards telehealth due to the comfortable setting of being at home.

\section{CONCLUSION AND RECOMMENDATIONS}

The null hypothesis was accepted. The results of the study support the hypothesis that technology provides tools for individuals to better understand, track, and interact with their health and healthcare teams. With each supporting objective, quantitative and qualitative results demonstrated adoption and positive perceptions related to consumer healthcare technology. Wearable technology was associated with high use, motivations heavily related to positive health activities or health-conscious behaviors, and regular use and checking of the device data. In the qualitative findings, wearable technology fostered a sense of accountability to the device that influenced activity behavior with multiple people expressing guilt if they miss activity goals. Additionally, the participants were influenced by competitive motivations both with others and themselves to beat activity goals. This implies the wearable device positively impacts the consumer to be more health and activity conscious. As consumers continue to track their health data, healthcare technology providers should increasingly connect that data into the larger healthcare ecosystem. For example, connecting exercise data to patient portals providing further centralized access for health management.

Digital patient portals were also heavily used motivated by bill paying, health records, paperwork, managing appointments, updating insurance, and requesting prescriptions. Responses indicated digital portals positively influenced consumer patient interactions. In the qualitative findings, time and access created more convenience, which created a preference for using the portal. This indicates that digital patient portals provide tools that positively impact the patient consumer perception. Additionally, most indicated using digital resources for filling and tracking prescriptions including confirming pharmacy status, checking payment details, requesting physician updates, and confirming shipping status with a heavy emphasis on text messaging. The qualitative findings indicated flexibility and immediacy provided consumers more control over their prescription process and created positive sentiments for digital management. As healthcare technology evolves, doctors providing patient portals should focus on the patient utility of the tool and provide cross-channel experiences. Patients should have the ability to use on mobile, tablet, and desktop with UI/UX and digital promotion of key features and functionality.

While most reported using telehealth services, there were mixed responses regarding the effectiveness of the treatment. This was supported by both the quantitative and qualitative research. The qualitative findings presented two themes further explaining the nuances to telehealth services. Users seeing a traditional doctor experienced uncertainty from feeling forced by the Covid-19 pandemic and a lack of trust in the doctor's ability to diagnose properly due to the setting. However, participants also expressed feeling comforted by the doctor's authority, even if the appointment didn't satisfy expectations or need. This suggests consumers don't perceive the service as effective but may still retain positive sentiment towards the physician.

The qualitative findings were different when applied to therapy telehealth services. Participants expressed a preference for remote therapy and found comfort in the setting of their own homes for this type of interaction. This suggest consumers are more receptive to therapy and find value in the digital interaction. The mixed results imply telehealth services are somewhat considered effective, but also have room for improvement. Providers should focus on helping patients understand what to expect, how to create a comfortable environment, and create pre-screening controls to direct those who require hands-on treatment into a physical office. This will help reduce friction for those patients who are optimistic about using the digital services and promote long-term adoption. 


\section{LIMITATIONS}

One limitation of the quantitative portion of the study is the sample size. Only 25 respondents took the survey. The small sample size makes the data not representative of the larger population of healthcare technology users. The study supports the need for further research with larger sample sizes to determine the relevance and impact of healthcare technologies. Another limitation is the age group of the respondents. Majority of the respondents were in the age range of 30-39 skewing the responses towards behaviors related to this age group. Future research should expand into other age groups to determine healthcare technology adoption differences as it relates to age. For the qualitative research, one limitation was the mixed adoption of the tools. Having a focus group of heavy users or non-users only will help refine the understanding of behaviors related to certain user segments.

\section{REFERENCES}

Canhoto, A.I., \& Arp, S. (2017). Exploring the factors that support adoption and sustained use of health and fitness wearables. Journal of Marketing Management, 33(1/2), 32-60. https://doiorg.ezproxy.bellevue.edu/10.1080/0267257X.2016.1234505

Cheung, M.L., Chau, K.Y., Lam, M.H.S., Tse, G., Ho, K.Y., Flint, S.W., . . Lee, K.Y. (2019). Examining Consumers' Adoption of Wearable Healthcare Technology: The Role of Health Attributes. International Journal of Environmental Research and Public Health, 16(13). https://doi-org.ezproxy.bellevue.edu/10.3390/ijerph16132257

Esmaeilzadeh, P. (2019). The Effects of Public Concern for Information Privacy on the Adoption of Health Information Exchanges (HIEs) by Healthcare Entities. Health Communication, 34(10), 1202-1211. https://doi-org.ezproxy.bellevue.edu/10.1080/10410236.2018.1471336

Eysenbach, G. (2001). What is e-health? Journal of Medical Internet Research, 3(2), e20. https://doiorg.ezproxy.bellevue.edu/10.2196/jmir.3.2.e20

Gariépy-Saper, K., \& Decarie, N. (2021). Privacy of electronic health records: A review of the literature. Journal of the Canadian Health Libraries Association (JCHLA), 42(1), 74-84. https://doiorg.ezproxy.bellevue.edu/10.29173/jchla29496

Ghaddar, S., Vatcheva, K.P., Alvarado, S.G., \& Mykyta, L. (2020). Understanding the Intention to Use Telehealth Services in Underserved Hispanic Border Communities: Cross-Sectional Study. Journal of Medical Internet Research, 22(9), e21012. https://doiorg.ezproxy.bellevue.edu/10.2196/21012

Goetz, C.M., Arnetz, J.E., Sudan, S., Arnetz, B.B., \& Gualano, M.R. (2020). Perceptions of virtual primary care physicians: A focus group study of medical and data science graduate students. PLOS ONE, 12.

Kasperbauer, T.J., \& Wright, D.E. (2020). Expanded FDA regulation of health and wellness apps. Bioethics, 34(3), 235-241. https://doi-org.ezproxy.bellevue.edu/10.1111/bioe.12674

Kinney, D.A., Nabors, L.A., Merianos, A.L., \& Vidourek, R.A. (2019). College Students' Use and Perceptions of Wearable Fitness Trackers. American Journal of Health Education, 50(5), 298307. https://doi-org.ezproxy.bellevue.edu/10.1080/19325037.2019.1642265

Klein, T.M., Augustin, M., Kirsten, N., \& Otten, M. (2020). Attitudes towards using electronic health records of patients with psoriasis and dermatologists: A cross-sectional study. BMC Medical Informatics and Decision Making, 20(1), 344. https://doiorg.ezproxy.bellevue.edu/10.1186/s12911-020-01302-y

Madrigal, L., \& Escoffery, C. (2019). Electronic Health Behaviors Among US Adults With Chronic Disease: Cross-Sectional Survey. Journal of Medical Internet Research, e11240. https://doiorg.ezproxy.bellevue.edu/10.2196/11240

McClellan, M.J., Florell, D., Palmer, J., \& Kidder, C. (2020). Clinician telehealth attitudes in a rural community mental health center setting. Journal of Rural Mental Health, 44(1), 62-73. https://doi-org.ezproxy.bellevue.edu/10.1037/rmh0000127 
Norman, C.D., \& Skinner, H.A. (2006). eHEALS: The eHealth Literacy Scale. Journal of Medical Internet Research, 8(4), e27. https://doi-org.ezproxy.bellevue.edu/10.2196/jmir.8.4.e27

Pratt, M.K. (2017). Have patient portals lived up to their potential? The technology delivers on some promised benefits, but more progress is needed to maximize its value to practices. Medical Economics, 94(3).

Radin, J.M., Wineinger, N.E., Topol, E.J., \& Steinhubl, S.R. (2020). Harnessing wearable device data to improve state-level real-time surveillance of influenza-like illness in the USA: A populationbased study. The Lancet Digital Health, 2(2), 85-93. https://doi.org/10.1016/S25897500(19)30222-5

Rosenbloom, S.T., Smith, J.R.L., Bowen, R., Burns, J., Riplinger, L., \& Payne, T.H. (2019). Updating HIPAA for the electronic medical record era. Journal of the American Medical Informatics Association: JAMIA, 26(10), 1115-1119. https://doiorg.ezproxy.bellevue.edu/10.1093/jamia/ocz090

Safavi, K., \& Kalis, B. (2020). How can leaders make recent digital health gains last? Accenture. Retrieved from https://www.accenture.com/us-en/insights/health/leaders-make-recent-digitalhealth-gains-last

Sisk, B., Alexander, J., Bodnar, C., Curfman, A., Garber, K., McSwain, S.D., \& Perrin, J.M. (2020). Pediatrician Attitudes Toward and Experiences With Telehealth Use: Results From a National Survey. Academic Pediatrics, 20(5), 628-635. https://doiorg.ezproxy.bellevue.edu/10.1016/j.acap.2020.05.004

Soliño-Fernandez, D., Ding, A., Bayro-Kaiser, E., \& Ding, E.L. (2019). Willingness to adopt wearable devices with behavioral and economic incentives by health insurance wellness programs: Results of a US cross-sectional survey with multiple consumer health vignettes. BMC Public Health, 19(1), 1-8. https://doi-org.ezproxy.bellevue.edu/10.1186/s12889-019-7920-9

Tavares, J., Goulão, A., \& Oliveira, T. (2018). Electronic Health Record Portals adoption: Empirical model based on UTAUT2. Informatics for Health \& Social Care, 43(2), 109-125. https://doiorg.ezproxy.bellevue.edu/10.1080/17538157.2017.1363759

Tavares, J., \& Oliveira, T. (2017). Electronic Health Record Portal Adoption: a cross country analysis. BMC Medical Informatics and Decision Making, 17(1), 1-17. https://doiorg.ezproxy.bellevue.edu/10.1186/s12911-017-0482-9

Turner, K., Hong, Y.-R., Yadav, S., Huo, J., \& Mainous, A.G. (2019). Patient portal utilization: Before and after stage 2 electronic health record meaningful use. Journal of the American Medical Informatics Association: JAMIA, 26(10), 960-967. https://doiorg.ezproxy.bellevue.edu/10.1093/jamia/ocz030

Uscher-Pines, L., Thompson, J., Taylor, P., Dean, K., Yuan, T., Tong, I., \& Mehrotra, A. (2020). Where Virtual Care Was Already a Reality: Experiences of a Nationwide Telehealth Service Provider During the COVID-19 Pandemic. Journal of Medical Internet Research, 22(12), e22727. https://doi-org.ezproxy.bellevue.edu/10.2196/22727

Weinzimmer, L.G., Dalstrom, M.D., Klein, C.J., Foulger, R., \& de Ramirez, S.S. (2021). The relationship between access to mental health counseling and interest in rural telehealth. Journal of Rural Mental Health. https://doi-org.ezproxy.bellevue.edu/10.1037/rmh0000179

Welch, B.M., Harvey, J., O’Connell, N.S., \& McElligott, J.T. (2017). Patient preferences for direct-toconsumer telemedicine services: A nationwide survey. BMC Health Services Research, 17(1), 17. https://doi-org.ezproxy.bellevue.edu/10.1186/s12913-017-2744-8 


\section{APPENDIX A}

Survey Questions

1. Do you use wearable health technologies such as Fitbit, Garmin, or Apple Watch?

Yes, No

2. How frequently do you wear your device?

Very Frequently, Frequently, Occasionally, Rarely, Very Rarely, Never

3. How frequently do you check your device data?

Very Frequently, Frequently, Occasionally, Rarely, Very Rarely, Never

4. Do you pair your device with other health tracking apps?

Yes, No

5. If yes, please specify which apps.

6. What motivates you to use your wearable device? (select all that apply)

Health metric tracking such as heart rate or calories burned, Daily Steps, Community or peer involvement, Health motivation such as ongoing goal maintenance, Weight loss, Athletic training, I don't wear one, Other

(Patient portals are an online portal provided for patients to access health records, manage prescriptions, schedule appointments, and interact with the care team.)

7. How often do you use digital portals offered by healthcare providers?

Most of the time, Some of the time, Seldom, Never

8. What are your motivations for using a patient portal? (select all that apply)

To request and manage my appointments, To pay my bill, To review my health records, To request prescriptions, To complete paperwork, To update my insurance information, Other: Open text

9. To what extent do you agree with the following statement? 'I prefer using a digital patient portal when interacting with healthcare providers.

Strongly Agree, Agree, Neutral, Disagree, Strongly Disagree

10. Does using a digital patient portal make your healthcare interactions easier?

Almost always, Often, Sometimes, Seldom, Never

11. When filling a prescription, how often do you prefer the doctor send the request directly to the pharmacy?

Most of the time, Some of the time, Seldom, Never

12. For recurring prescriptions, how likely are you to order online?

Not likely, Somewhat likely, Very likely

13. How do you use digital tools to manage prescriptions? (Check all that apply)

To confirm pharmacy status

To request updates from my doctor

To check payment details

To confirm shipping status

Other: open text

14. Have you used telehealth services such as virtual doctor visits?

Yes, No

15. When deciding to use telehealth services, rank the importance of each influencing factor with 1 being the most important and 5 the least important.

1. Time convenience

2. Location convenience

3. Accurate symptom diagnosis

4. Preferred doctor

5. Reason for visit

16. Were the telehealth services used sufficient for your needs?

Very Good

Good 
Acceptable

Poor

Very Poor

17. Would you choose telehealth over an in-person doctors visit?

Definitely

Very Probably

Probably

Possibly

Probably Not

Definitely Not

18. What is your age group?

17 or younger

$18-20$

21-29

30-39

$40-49$

50-59

60 or older

19. Are you insured?

Yes

No

20. Gender

Male

Female

Other

Prefer not to answer

\section{APPENDIX B}

Survey Questions and Results

1. Do you use wearable health technologies such as Fitbit, Garmin, or Apple Watch?

Yes $=60 \%$ (15) No $=40 \%$ (10)

2. How frequently do you wear your device?

Very Frequently $=39 \%$ (7), Frequently $=17 \%$ (3), Occasionally $=22 \%$ (4), Rarely $=0 \%$ (0), Very Rarely $=6 \%$ (1), Never 17\% (3)

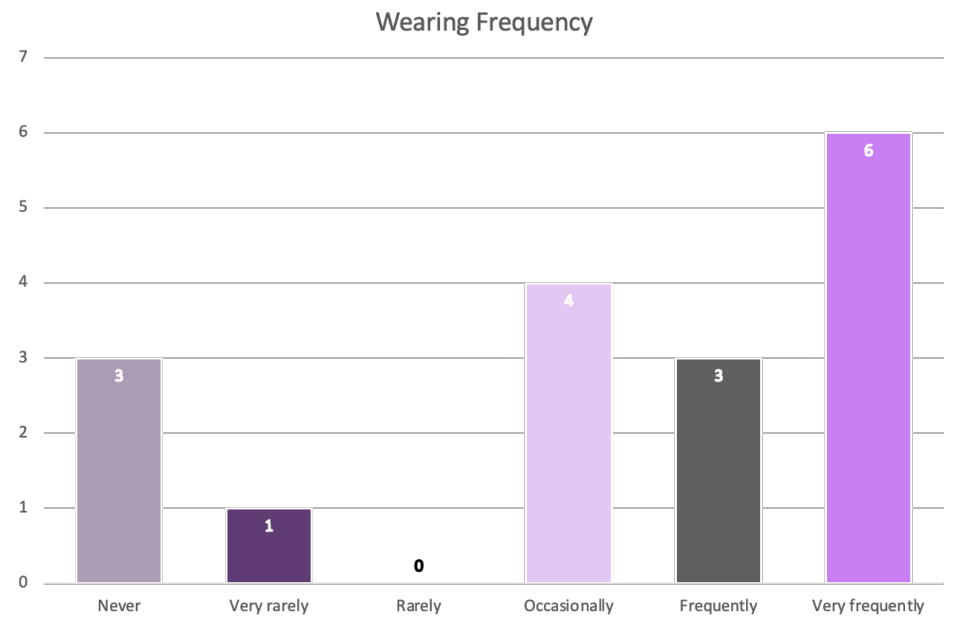


3. How frequently do you check your device data?

Very Frequently $=17 \%$ (3), Frequently $=28 \%$ (5), Occasionally $=28 \%(5)$, Rarely $=6 \%$ (1), Very Rarely $=11 \%$ (2), Never $11 \%$ (2)

Checking Frequency

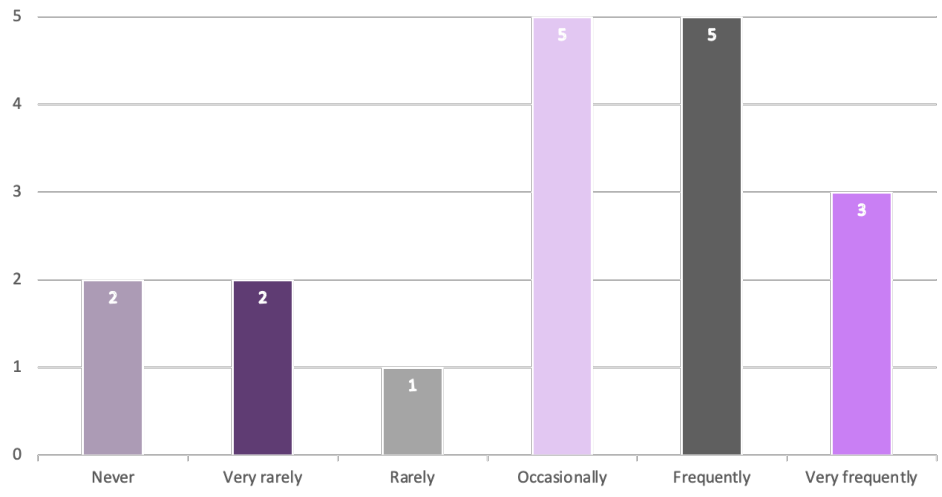

4. Do you pair your device with other health tracking apps?

Yes $=24 \%(5)$, No $=76 \%(21)$

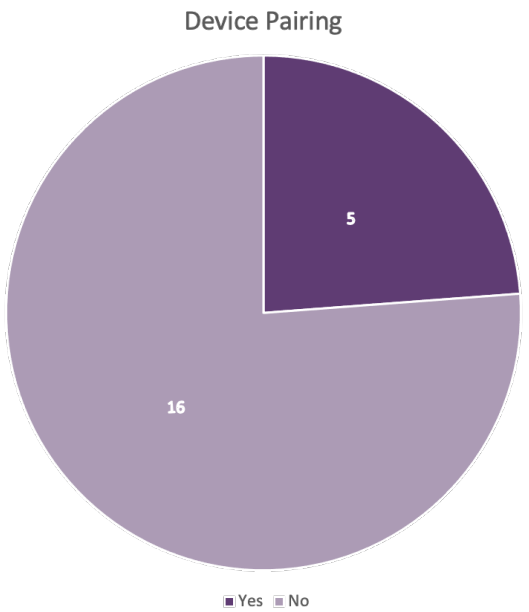

5. If yes, please specify which apps.

Run tracker, My Fitness Pal, Map my run, Activity, health, workout, Apple health activity and workouts, UHC Motion app.

6. What motivates you to use your wearable device? (select all that apply)

Health metric tracking such as heart rate or calories burned $=55 \%(12)$, Daily Steps $=59 \%(13)$, Community or peer involvement $=9 \%$ (2), Health motivation such as ongoing goal maintenance $=$ $36 \%$ (8), Weight loss $=41 \%$ (9), Athletic training $=27 \%$ (6), I don't wear one $=27 \%$ (6), Other $=$ $0 \%(0)$ 


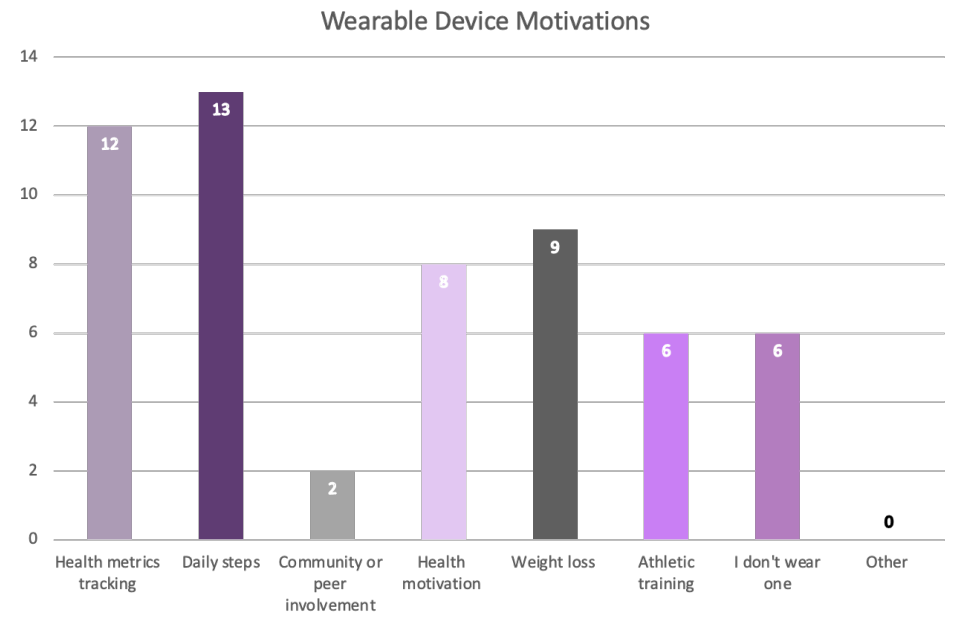

(Patient portals are an online portal provided for patients to access health records, manage prescriptions, schedule appointments, and interact with the care team.)

7. How often do you use digital portals offered by healthcare providers?

Most of the time $=40 \%$ (10), Some of the time $=32 \%$ (8), Seldom $=20 \%$ (5), Never $=8 \%(2)$

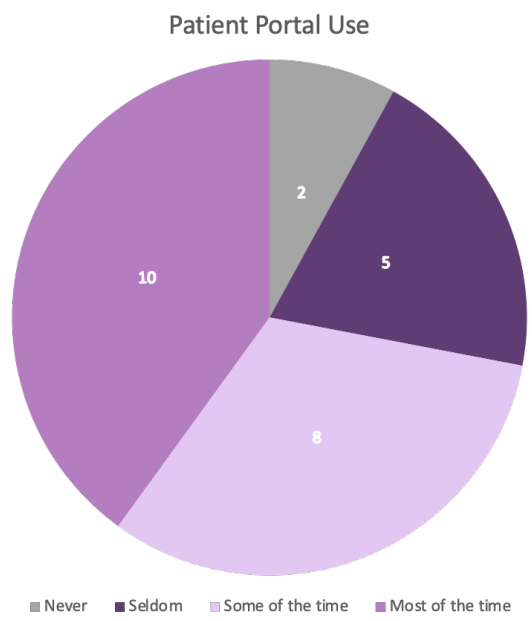

8. What are your motivations for using a patient portal? (select all that apply)

To request and manage my appointments $=64 \%(16)$

To pay my bill $=68 \%(17)$

To review my health records $=68 \%(17)$

To request prescriptions $=40 \%(10)$

To complete paperwork $=68 \%(17)$

To update my insurance information $=52 \%$ (13)

Other: Open text $=4 \%(1)$ 


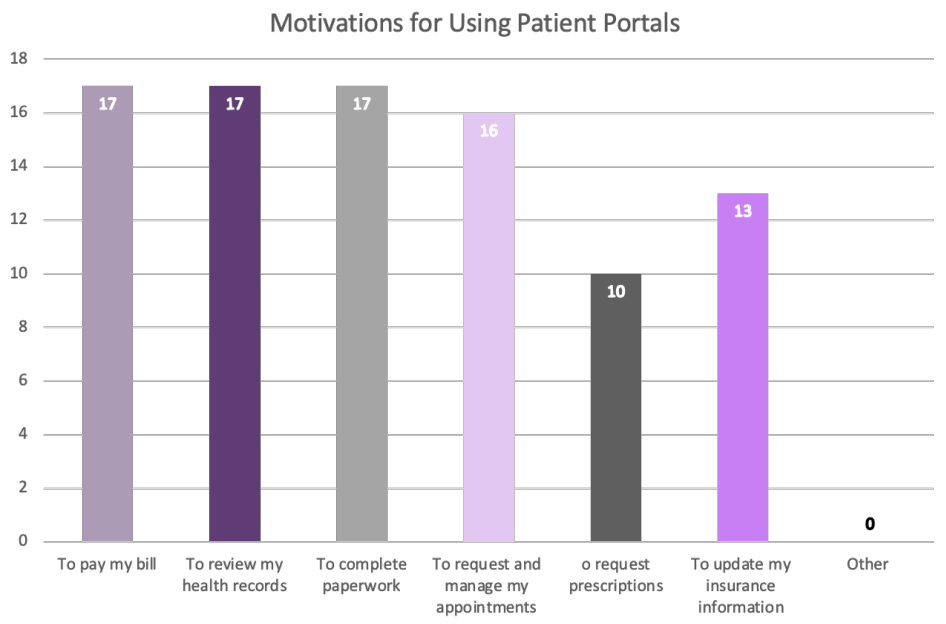

9. To what extent do you agree with the following statement? 'I prefer using a digital patient portal when interacting with healthcare providers."

Strongly Agree $=28 \%(7)$, Agree $=32 \%(8)$, Neutral $=36 \%(9)$, Disagree $=4 \%(1)$

Strongly Disagree $=0 \%(0)$

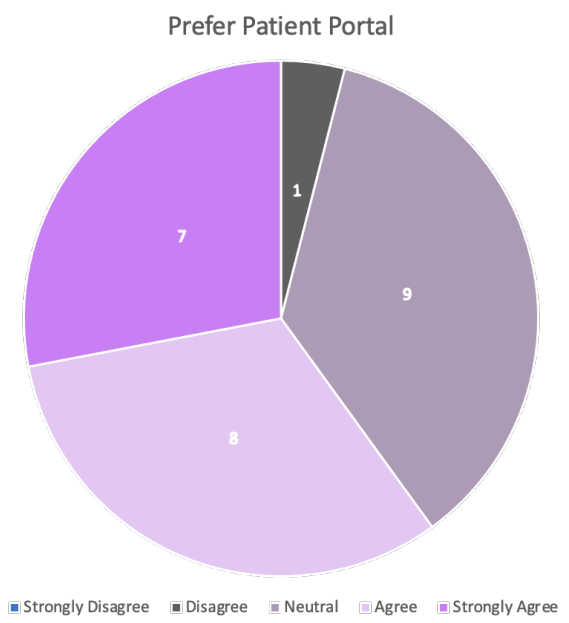

10. Does using a digital patient portal make your healthcare interactions easier?

Almost always $=26 \%(6)$, Often $=35 \%(8)$, Sometimes $=30 \%(7)$, Seldom $=9 \%(2)$

Never $=0 \%(0)$ 


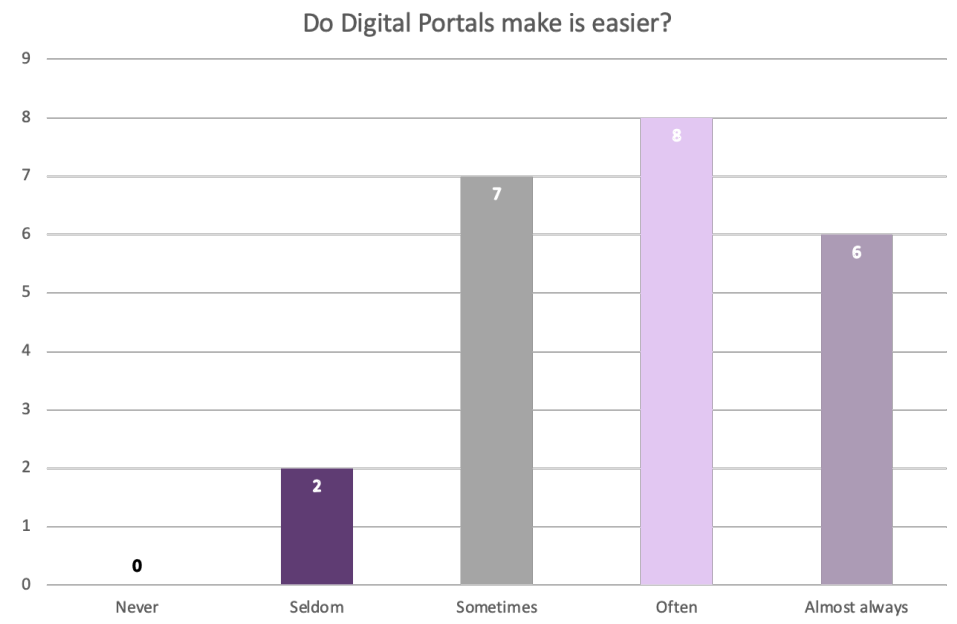

11. When filling a prescription, how often do you prefer the doctor send the request directly to the pharmacy?

Most of the time $=96 \%(23)$, Some of the time $=0 \%(0)$, Seldom $=0 \%(0)$, Never $=4 \%(1)$

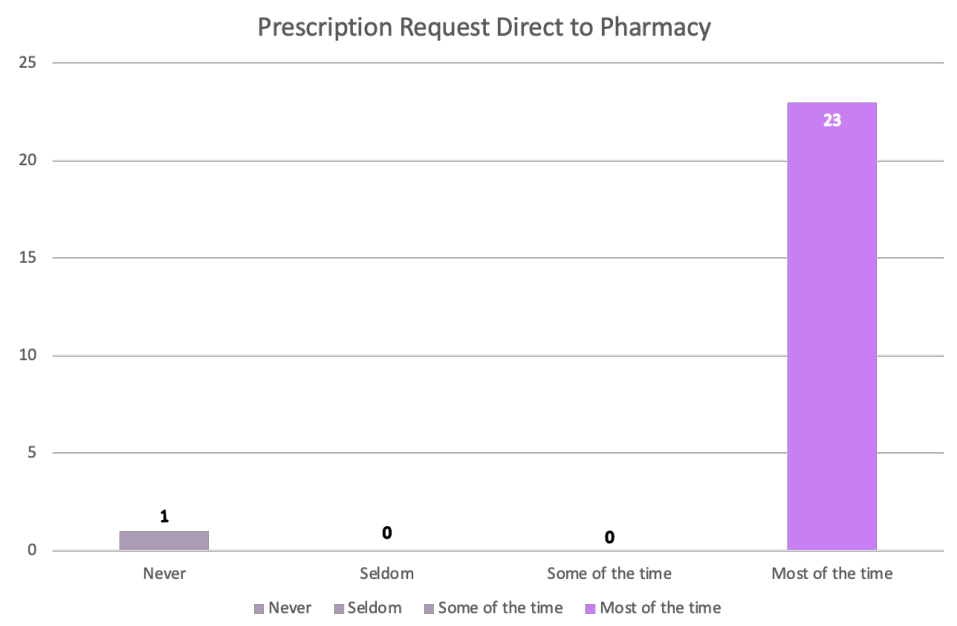

12. For recurring prescriptions, how likely are you to order online?

Not likely $=14 \%(3)$, Somewhat likely $=32 \%(7)$, Very likely $=55 \%(12)$

13. How do you use digital tools to manage prescriptions? (Check all that apply)

To confirm pharmacy status $=70 \%(15)$

To request updates from my doctor $=35 \%(8)$

To check payment details $=48 \%(11)$

To confirm shipping status $=22 \%(5)$

Other: open text $=13 \%$ (3) (open responses: Hardly ever have prescriptions, I do not use digital tools to manage my prescriptions, I typically take care of my prescriptions over the phone) 


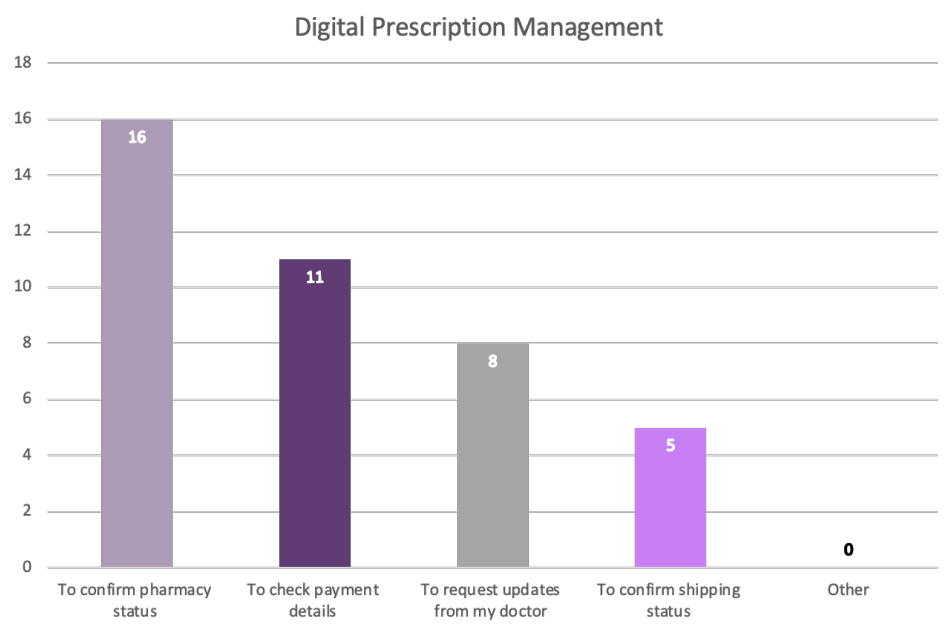

14. Have you used telehealth services such as virtual doctor visits? Yes $=76 \%(19)$, No $=24 \%(6)$

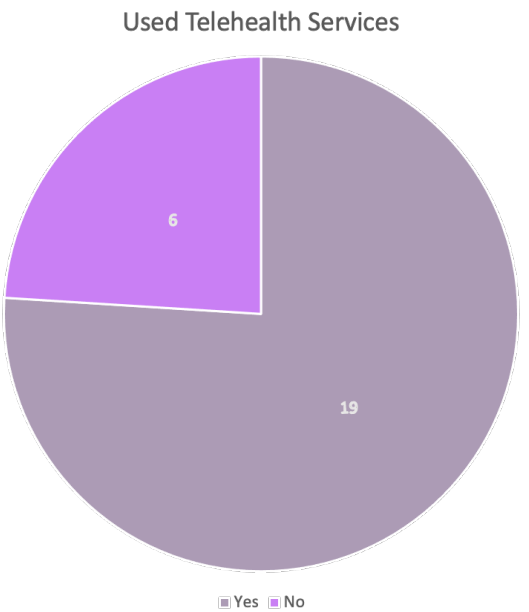

15. When deciding to use telehealth services, rank the importance of each influencing factor with 1 being the most important and 5 the least important.

1. Time convenience $=1.4$

2. Location convenience $=2.2$

3. Accurate symptom diagnosis $=3.68$

4. Preferred doctor $=3.8$

5. $\quad$ Reason for visit $=3.9$

16. Were the telehealth services used sufficient for your needs?

Very Good $=14 \%(3)$, Good $=45 \%(10)$, Acceptable $=32 \%(7)$, Poor $=5 \%(1)$, Very Poor $=5 \%$ (1) 


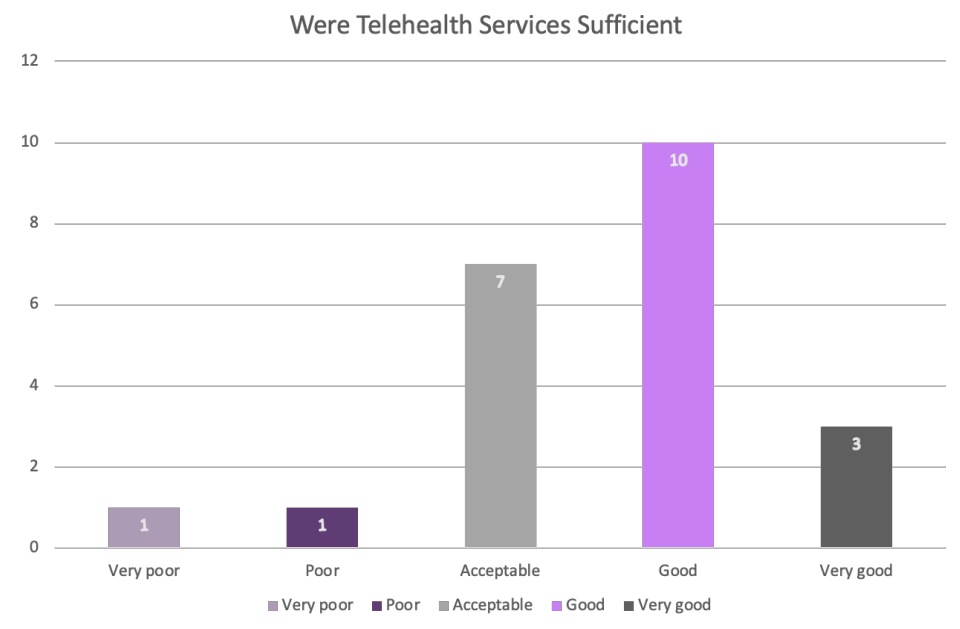

17. Would you choose telehealth over an in-person doctors visit?

Definitely $=8 \%(2)$

Very Probably $=0 \%(0)$

Probably $=17 \%$ (4)

Possibly $=46 \%(11)$

Probably Not $=13 \%(3)$

Definitely Not $=17 \%$ (4)

18. What is your age group?

17 or younger $=0 \%(0)$

$18-20=0 \%(0)$

$21-29=0 \%(0)$

$30-39=68 \%(17)$

$40-49=16 \%(4)$

$50-59=12 \%(3)$

60 or older $=4 \%$ (1)

19. Are you insured?

Yes $=88 \%(22)$

$\mathrm{No}=12 \%(3)$

20. Gender

Male $=36 \%(9)$

Female $=64 \%(16)$

Other $=0 \%(0)$

Prefer not to answer $=0 \%(0)$

\section{APPENDIX C}

\section{Focus Group Outline}

Objectives

To identify if wearable technology positively impacts a consumer to be more health conscious.

- Describe how you use a wearable device(s).

- Why is it important to you or not important to you to wear a device?

- How does wearing a device affect your health?

To confirm if digital patient portals, such as digital patient files or appointment setting mechanisms, help the end user interact more efficiently with the healthcare service.

- Describe your interactions with doctor/patient portals. 
- Describe why you like or dislike using them?

To understand if people find value when using digital resources for filling and tracking prescriptions. For example, sending the prescription request directly to the pharmacy digitally or tracking by an app. To reiterate, all answers are confidential and will remain anonymous outside of this group.

- How do you manage your prescriptions?

- Why do you prefer or not prefer to use physical paper-to-pharmacy drop off for your prescriptions?

To understand if telehealth services are viewed as effective by the individual using them.

- Why would you use or not use a telehealth service?

- Describe your interactions with telehealth services.

- How did the telehealth service meet your expectations?

\section{APPENDIX D}

Focus Group Summary

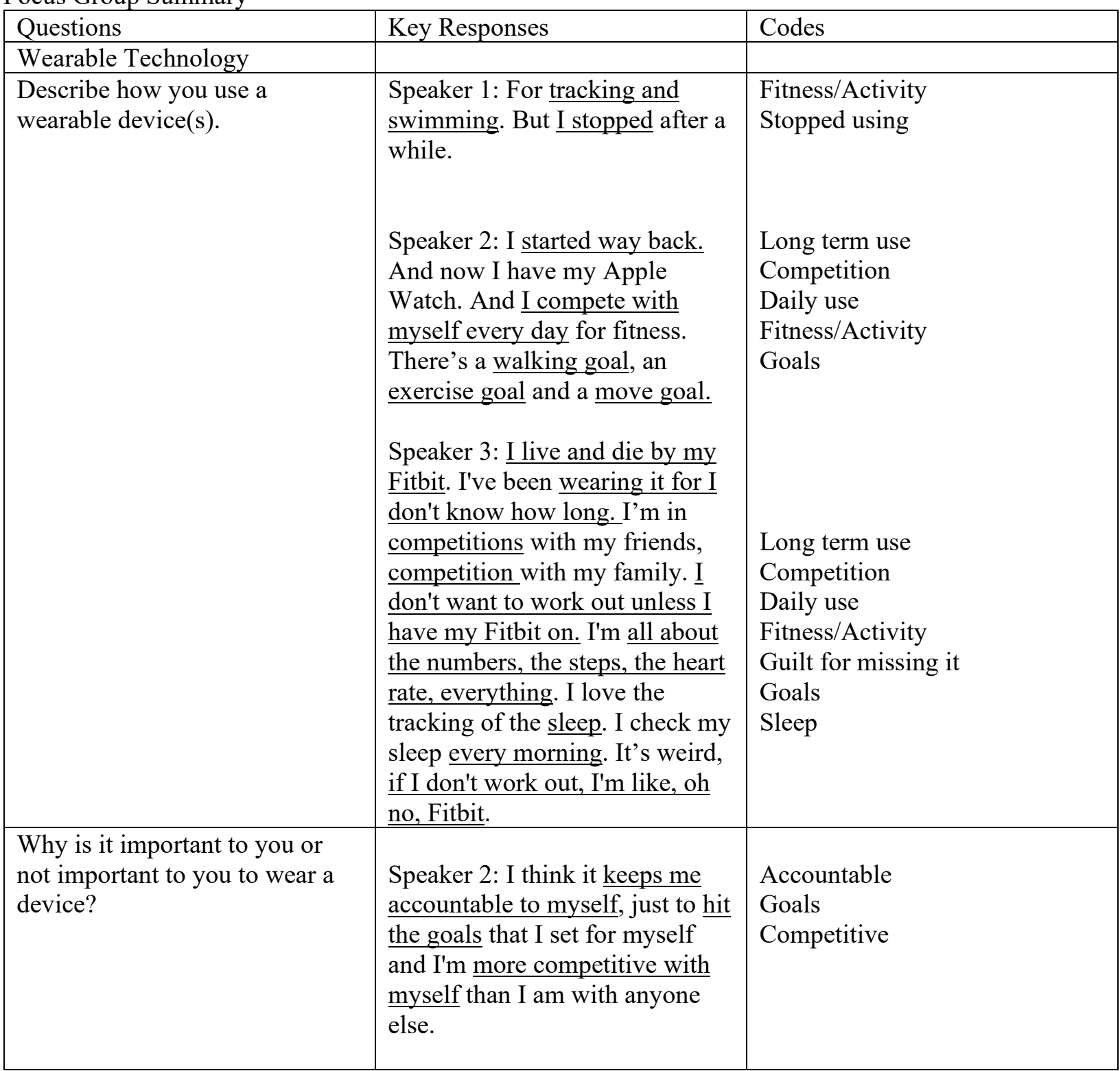




\begin{tabular}{|c|c|c|}
\hline & $\begin{array}{l}\text { Speaker 3: I mean it keeps you } \\
\text { accountable. And I don't know, I } \\
\text { like to get a certain amount of } \\
\text { steps like before I start work, } \\
\text { during my lunch break. I don't } \\
\text { know, it just kind of makes me } \\
\text { move more. I'm also competitive } \\
\text { with my sister. } \\
\text { Speaker 6: When I was pretty } \\
\text { consistent with it, it was it was } \\
\text { more of a motivation for me. } \\
\text { Whenever I would hit like, you } \\
\text { know, that } 10,000 \text { steps a day. }\end{array}$ & $\begin{array}{l}\text { Accountable } \\
\text { Goals } \\
\text { Competitive } \\
\text { Activity } \\
\text { Motivating if using } \\
\text { Goals }\end{array}$ \\
\hline $\begin{array}{l}\text { How does wearing a device } \\
\text { affect your health? }\end{array}$ & $\begin{array}{l}\text { Speaker 3: My workouts, I have } \\
\text { a goal for my heart rate. So even } \\
\text { if it's just like, I've got to get to } \\
\text { a certain point, how much will } \\
\text { you push yourself. So like in my } \\
\text { classes, if I don't get to this } \\
\text { thing, I'm like, okay, I was half- } \\
\text { assing it. I know what point I } \\
\text { have pushed myself for it to get } \\
\text { to that level. That's what I strive } \\
\text { for. } \\
\text { Speaker } 2 \text { : Mine is more about } \\
\text { time. I just know that I want to } \\
\text { get at least, you know, } 30 \text { to } 45 \\
\text { to } 60 \text { minutes of exercise a day. } \\
\text { And so it helps to just remind } \\
\text { me. If I get to the end of the day, } \\
\text { and I haven't done it, then I go } \\
\text { hop on the treadmill and get it } \\
\text { done. } \\
\text { Speaker 5: I kind of struggle } \\
\text { with taking things to like } \\
\text { extremes. When I used a } \\
\text { wearable like, it got a little } \\
\text { intense. And I was like, these } \\
\text { are unhealthy behaviors. }\end{array}$ & $\begin{array}{l}\text { Fitness goals } \\
\text { Reminder } \\
\text { Guilt for missing it } \\
\text { Push yourself } \\
\\
\text { Negative/extreme } \\
\text { Unhealthy behavior }\end{array}$ \\
\hline \multicolumn{3}{|l|}{ Patient Portals } \\
\hline $\begin{array}{l}\text { Describe your interactions with } \\
\text { doctor/patient portals. }\end{array}$ & $\begin{array}{l}\text { Speaker 1: I use mine a lot. For } \\
\text { my doctor scheduling stuff, } \\
\text { random questionnaires, if I need } \\
\text { a prescription filled out. Either } \\
\text { the app or a website. }\end{array}$ & $\begin{array}{l}\text { Frequent user } \\
\text { Utility based } \\
\text { Digital savvy }\end{array}$ \\
\hline
\end{tabular}




\begin{tabular}{|c|c|c|}
\hline & $\begin{array}{l}\text { Speaker 2: I use mine a lot too. I } \\
\text { use it for everything. Questions, } \\
\text { scheduling, payments, video } \\
\text { calls. And I have } 100 \text { doctors, so } \\
\text { pretty much a lot. But I'm really } \\
\text { glad to have it. } \\
\text { Speaker 6: I find it super helpful } \\
\text { as well. The only thing that I } \\
\text { don't like is having an } \\
\text { appointment virtually. Like I'd } \\
\text { rather do that in person, but } \\
\text { everything else. Absolutely }\end{array}$ & $\begin{array}{l}\text { Frequent user } \\
\text { Utility based } \\
\text { Consolidated } \\
\text { Appreciative } \\
\\
\text { Appreciative } \\
\text { Dislike telehealth }\end{array}$ \\
\hline $\begin{array}{l}\text { Describe why you like or dislike } \\
\text { using them? }\end{array}$ & $\begin{array}{l}\text { Speaker 5: I didn't like them } \\
\text { until now that I have Kaiser and } \\
\text { all the doctors are in the same } \\
\text { network, all of the information } \\
\text { is in the same network. And it's } \\
\text { a really easy website to use. But } \\
\text { before that, I was like, I'm not a } \\
\text { tech savvy person. I do not like } \\
\text { to navigate, like, strange } \\
\text { technology. } \\
\text { Speaker 4: Yeah, I think } \\
\text { convenience is the biggest thing, } \\
\text { like the biggest pro I suppose. } \\
\text { The only con I would have is } \\
\text { having multiple accounts. I like } \\
\text { not having to, you know call } \\
\text { somebody and having to wait on } \\
\text { hold. You don't have to do that } \\
\text { anymore. }\end{array}$ & $\begin{array}{l}\text { Disliked multiple accounts } \\
\text { Consolidated } \\
\text { Easy } \\
\text { Not tech savvy }\end{array}$ \\
\hline \multicolumn{3}{|l|}{ Digital Prescriptions } \\
\hline $\begin{array}{l}\text { How do you manage your } \\
\text { prescriptions? }\end{array}$ & $\begin{array}{l}\text { Speaker 4: My doctors sends it } \\
\text { in initially, but then once he's } \\
\text { sent it in, I do it all through } \\
\text { texts. Like the pharmacy sends } \\
\text { me a text saying, hey, you're due } \\
\text { for a refill. Do you want it or } \\
\text { not? And I just text back yes. } \\
\text { And then I go pick it up. } \\
\text { Speaker 2: Instead of waiting for } \\
\text { the pharmacy to do it, I just go } \\
\text { in my portal and ask my doctor } \\
\text { to do it and they send it to the }\end{array}$ & $\begin{array}{l}\text { Takes lead managing } \\
\text { Text message } \\
\text { Easy } \\
\text { Takes lead managing }\end{array}$ \\
\hline
\end{tabular}




\begin{tabular}{|c|c|c|}
\hline & $\begin{array}{l}\text { pharmacy. It's a little more } \\
\text { control because you know that } \\
\text { your doctor is going to do it and } \\
\text { you're not really so sure about } \\
\text { the pharmacy }\end{array}$ & $\begin{array}{l}\text { Uses portal } \\
\text { More control } \\
\text { Doctor's authority/trust }\end{array}$ \\
\hline $\begin{array}{l}\text { Why do you prefer or not prefer } \\
\text { to use physical paper-to- } \\
\text { pharmacy drop off for your } \\
\text { prescriptions? }\end{array}$ & 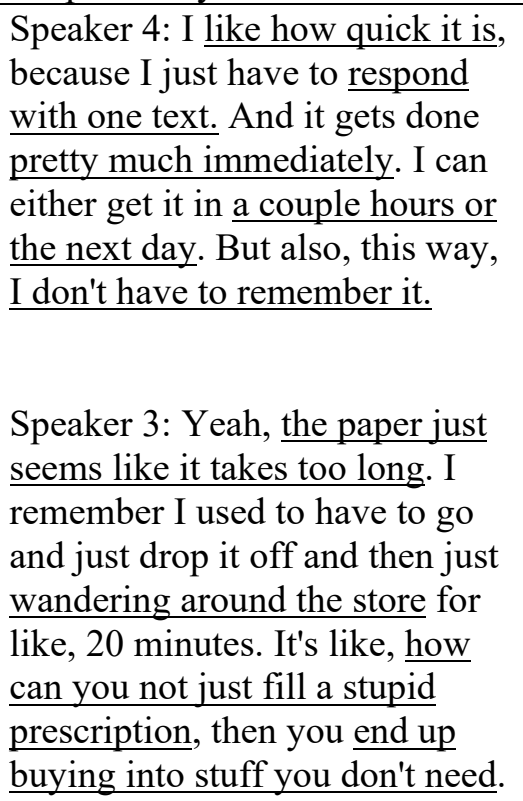 & $\begin{array}{l}\text { Text message } \\
\text { Flexible } \\
\text { Immediacy } \\
\text { Reminder } \\
\text { Paper is slow } \\
\text { Time/money wasted }\end{array}$ \\
\hline \multicolumn{3}{|l|}{ Telehealth } \\
\hline $\begin{array}{l}\text { Why would you use or not use a } \\
\text { telehealth service? }\end{array}$ & $\begin{array}{l}\text { Speaker 1: Honestly, if it weren't } \\
\text { COVID I would never use it. I } \\
\text { don't know. Whatever like the } \\
\text { lighting is in your house is, they } \\
\text { can't tell what color the back of } \\
\text { your throat is. } \\
\text { Speaker 6: I was having like, a } \\
\text { lot of issues with my, with my } \\
\text { ears in my head. So, like, the } \\
\text { virtual experience was just like, } \\
\text { I didn't know how they were } \\
\text { actually going to help me if they } \\
\text { couldn't see what was going on, } \\
\text { like inside my ears. }\end{array}$ & $\begin{array}{l}\text { Covid forced use } \\
\text { Home setting adds pressure } \\
\text { Distrust in ability to diagnose } \\
\text { Distrust in ability to diagnose } \\
\text { Couldn't see/not hands-on }\end{array}$ \\
\hline $\begin{array}{l}\text { Describe your interactions with } \\
\text { telehealth services. }\end{array}$ & $\begin{array}{l}\text { Speaker 5: I was having like, } \\
\text { sinus problems, which they }\end{array}$ & Distrust in ability to diagnose \\
\hline
\end{tabular}




\begin{tabular}{|c|c|c|}
\hline & $\begin{array}{l}\text { couldn't look into my nose, and I } \\
\text { got on the telehealth and they're } \\
\text { like, somebody should look in } \\
\text { your nose. But it also reassured } \\
\text { me. Like a doctor told me when } \\
\text { I need to see somebody. I also } \\
\text { did, like therapy after covid. I } \\
\text { would actually prefer it. You get } \\
\text { to be in your own house. You're } \\
\text { super comfortable. You're } \\
\text { talking to somebody that you } \\
\text { know. } \\
\text { Speaker } 2: \text { The last video one } \\
\text { that I did was I was freaking out } \\
\text { over something and I got on } \\
\text { there and showed it to my doctor } \\
\text { and she's like, dude, you're fine. } \\
\text { And I was like, Okay. So it } \\
\text { really helped the other way to } \\
\text { say like, it's okay. Calm down. } \\
\text { Nothing's wrong. You're fine. }\end{array}$ & $\begin{array}{l}\text { Doctor provided authority/trust } \\
\text { Therapy uses } \\
\text { Preference } \\
\text { Comfort of own home }\end{array}$ \\
\hline $\begin{array}{l}\text { How did the telehealth service } \\
\text { meet your expectations? }\end{array}$ & $\begin{array}{l}\text { Speaker 4: I thought it was } \\
\text { going to be a little more } \\
\text { awkward than it was. So I guess } \\
\text { maybe exceeded expectations. } \\
\text { Not being as awkward or as } \\
\text { anxiety inducing as I expected. } \\
\text { Speaker 5: It was way easier } \\
\text { than I thought. I don't know } \\
\text { what I was expecting but it was } \\
\text { like, oh, there's a doctor on my } \\
\text { screen and I can ask them what I } \\
\text { need to ask them. } \\
\begin{array}{l}\text { Speaker 3: I think that would be } \\
\text { interesting to have like a therapy } \\
\text { session. I would feel more } \\
\text { comfortable with that at home } \\
\text { on a computer or your phone } \\
\text { rather than going somewhere. }\end{array}\end{array}$ & $\begin{array}{l}\text { Met/exceeded expectations } \\
\text { Expected awkward, but wasn't } \\
\text { Easier than expected } \\
\text { Doctor provided authority/trust } \\
\text { Therapy } \\
\text { Comfort } \\
\text { Home }\end{array}$ \\
\hline
\end{tabular}

